\title{
CRITERIOS DELIMITADORES DEL CONCEPTO DE RESIDENCIA HABITUAL EN LAS CRISIS MATRIMONIALES INTRACOMUNITARIAS: A PROPÓSITO DEL AUTO DE 12 DE NOVIEMBRE DE 2020 DE LA SECCIÓN DÉCIMA DE LA AUDIENCIA PROVINCIAL DE VALENCIA
}

\author{
DELIMITING CRITERIA OF THE HABITUAL RESIDENCE \\ CONCEPT IN THE INTRACOMUNITY MARRIAGE CRISIS: \\ JUDICIAL ORDER OF NOVEMBER 12, 2020 OF THE TENTH \\ SECTION OF THE VALENCIA PROVINCIAL COURT
}

\author{
Marta Casado Abarquero \\ Profesora Contratada Doctora \\ Universidad de Deusto \\ ORCID: 0000-0002-7228-4044
}

Recibido: 16.06.2021 / Aceptado: 08.07.2021

DOI: https://doi.org/10.20318/cdt.2021.6285

\begin{abstract}
Resumen: En el presente auto la Audiencia Provincial de Valencia aborda una vez más el problema de fijar los límites, en frecuentes ocasiones difusos, entre el cambio de la residencia habitual o el mero traslado temporal. Concretamente, debe decidir si el traslado de residencia habitual con vocación de permanencia que resulta frustrado al cabo de dos únicos meses por la existencia de una crisis matrimonial sobrevenida e inesperada, determina la pérdida del carácter habitual de la residencia anterior.
\end{abstract}

Palabras clave: residencia habitual, crisis matrimonial, responsabilidad parental, Reglamento 2201/2003.

Abstract: In the present order, the Provincial Court of Valencia faces once again the frequent problem of setting the limits, often blurred, between the change of the habitual residence or its mere temporary transfer. Specifically, it must decide whether the transfer of the habitual residence with the intention to stay which is frustrated after only two months due to the existence of an unexpected marital crisis, determines the loss of the habitual character of the previous habitual residence.

Keywords: habitual residence, marital crisis, parental responsibility, Regulation 2201/2003.

Sumario: I. Antecedentes de hecho. II. Competencia judicial internacional en materia de crisis matrimoniales intracomunitarias: Marco jurídico. 1. El Reglamento Bruselas II-bis: delimitación de su ámbito de aplicación. 2. El Reglamento Bruselas II-bis: Foros de competencia judicial internacional en materia de divorcio, separación judicial y nulidad matrimonial. 3. El Reglamento Bruselas II-bis: Foros de competencia judicial internacional en materia de responsabilidad parental. III. Criterios delimitadores el concepto "Residencia Habitual" en el Reglamento Bruselas II-bis. 1. Intencionalidad de permanencia o animus manendi. 2. Duración y regularidad de la residencia. 3. Integración en un entorno social y familiar. IV. Valoración final. 


\section{Antecedentes de hecho}

1. El matrimonio compuesto por Marta y Pablo tenía fijado su domicilio en Valencia desde octubre de 2015. En noviembre de 2017 la esposa aceptó un trabajo en Francia pero la pareja acordó que el padre se quedaría en Valencia con los hijos hasta ver cómo evolucionaba el trabajo de ella en el país galo. En marzo de 2019 el matrimonio consideró el trasladar definitivamente su residencia a Francia. Por ello, matricularon a los hijos menores de edad en un colegio francés para el curso 2019-2020. Además, alquilaron una vivienda de mayores dimensiones en una localidad cercana a París, más cómodo para las rutinas familiares que el pequeño apartamento en el que Marta vivía en la capital francesa. Finalmente, el 24 de julio de 2019 la familia subió a un avión sin billete de vuelta para trasladarse a la ciudad francesa, donde estuvieron viviendo juntos hasta el 24 de agosto, fecha en la que el matrimonio tuvo una fuerte discusión que motivó la ruptura matrimonial.

2. En la resolución comentada se aportan otros datos fácticos que no parecen concluyentes para la resolución del caso. Así, se nos dice que “(...) que los niños estaban matriculados para el curso 20192020 en un colegio de Valencia. Sin embargo, se desconoce el momento en que fueron matriculados y si la matriculación se hizo con el conocimiento y el consentimiento de ambos progenitores, al contrario de lo que ocurría con la matricula del colegio francés, de la que se conoce su fecha exacta de solicitud y que se hizo con el consentimiento de ambos progenitores. (...) Tampoco constan las razones por las que el contrato de arrendamiento del domicilio de Valencia no fue prorrogado. Tan solo consta la voluntad contraria del arrendador de prorrogar el contrato, sin que pueda saberse si fue una decisión de la demandada comunicada al arrendador. (...) La tarjeta sanitaria provisional de los niños se encuentra emitida en septiembre de 2019, cuando ya se había producido la discusión de la pareja que motivó definitivamente la ruptura matrimonial. La mera inscripción en el padrón, solo puede tener efectos administrativos, debiendo vencer el criterio del lugar donde realmente radicó la familia por última vez". En definitiva, se trata de pruebas aportadas por el progenitor (o incluso podríamos hablar de "pruebas construidas" por éste) para intentar revertir la decisión de trasladar de forma permanente el domicilio de la familia a Francia.

3. En este contexto de crisis matrimonial, Pablo interpone demanda de divorcio ante los Juzgados de Primera Instancia de Valencia. En ella se solicitaba la disolución del matrimonio y la determinación de las medidas definitivas derivadas de la disolución matrimonial, incluidas las relacionadas con los hijos comunes. Sin embargo, con fecha 13 de enero de 2020, el Juzgado de Primera Instancia $n .^{\circ} 26$ de Valencia estimó la declinatoria presentada por la esposa y declaró la falta de competencia judicial internacional de los órganos jurisdiccionales españoles para conocer de la misma. El auto fue recurrido ante la Audiencia Provincial de Valencia, dando lugar al auto que es objeto de análisis en este trabajo ${ }^{1}$.

4. Como puede intuirse, el eje sobre el que gira el debate jurídico es la definición del concepto de última residencia habitual de la familia. El recurso de apelación se fundamenta en que Valencia es el lugar de residencia habitual de la familia, mientras que la oposición al recurso de apelación se centra en defender que ésta radica en el país vecino.

\section{Competencia judicial internacional en materia de crisis matrimoniales intracomunitarias: Marco jurídico}

\section{El Reglamento Bruselas II-bis: delimitación de su ámbito de aplicación}

5. El marco jurídico de aplicación al caso viene determinado por el Reglamento (CE) $\mathrm{n}^{\mathrm{o}}$ 2201/2003 del Consejo, de 27 de noviembre de 2003, relativo a la competencia, el reconocimiento y la

${ }^{1}$ ECLI:ES:APV:2020:3271A 
ejecución de resoluciones judiciales en materia matrimonial y de responsabilidad parental, por el que se deroga el Reglamento (CE) n ${ }^{\circ}$ 1347/2000². También conocido como Reglamento Bruselas II-bis.

6. En ocasiones los juzgados han interpretado incorrectamente el ámbito de aplicación de este instrumento jurídico. No es infrecuente que nuestros órganos jurisdiccionales hayan basado su competencia judicial internacional en la LOPJ en supuestos en que, pese a haber un elemento internacional (en este caso el traslado de la familia a Francia), ambos cónyuges y sus hijos comunes son nacionales españoles ${ }^{3}$. Por ello, creemos que es necesario hacer una breve referencia al ámbito de aplicación de este instrumento jurídico comunitario, que introduce en los Estados miembros normas uniformes sobre competencia judicial internacional (Capítulo II) y sobre reconocimiento de resoluciones judiciales (Capítulo III) en materia matrimonial y de responsabilidad parental.

7. El ámbito de aplicación material viene definido por el artículo 1 del mismo. Así, el Reglamento se aplica a las materias civiles relativas: a) al divorcio, la separación judicial y la nulidad matrimonial; b) a la atribución, el ejercicio, la delegación, la restricción o la finalización de la responsabilidad parental. Esta última, a título ilustrativo, incluye el derecho de custodia y el derecho de visita, la tutela, el acogimiento y las funciones de toda persona u organismo encargado de ocuparse de la persona o de los bienes del menor, de representarlo o de prestarle asistencia (art. 1.2) ${ }^{4}$.

8. Mayor confusión plantea la comprensión del ámbito de aplicación personal del Reglamento comunitario. En principio, según el artículo 6 RB II-bis, los foros de competencia judicial internacional previstos en los artículos 3 a 5 serán aplicables en los supuestos en que uno de los cónyuges tenga su residencia habitual en el territorio de un Estado miembro, o sea nacional de uno de ellos (o, en el caso de Irlanda, tenga su «domicile» en territorio irlandés. Sin embargo, si ninguno de los órganos jurisdiccionales de un estado miembro resultara competente con arreglo a estos preceptos, los órganos jurisdiccionales de otro Estado miembro podrán declararse competentes en virtud de los foros previstos en sus normas de producción interna, con independencia de la nacionalidad del demandado, y de que éste tenga o no su residencia habitual en un Estado miembro. Y ello siempre que el demandante sea un nacional de un Estado miembro que, a su vez, tenga su residencia habitual en el territorio de otro Estado miembro (artículo 7) .

9. Pocos problemas debiera plantear en la actualidad (tras más de 15 años desde su entrada en vigor) la correcta aplicación del ámbito de aplicación temporal y territorial. En relación con el primero, el Reglamento Bruselas II-bis se viene aplicando a las acciones judiciales ejercitadas desde el 1 de marzo de 2005 (artículo 64.1). Y lo mismo sucede con su ámbito de aplicación espacial, este instrumento

\footnotetext{
${ }^{2}$ DOUE L 338 de 23 de diciembre de 2003.

3 A. QuiÑones EsCÁMEZ, “¿Cuándo se aplica el Reglamento Bruselas II bis? El TJUE se pronuncia sobre su ámbito de aplicación”, Revista de Derecho Comunitario Europeo, n. ${ }^{\circ} 30$, 2008, pp. 457-482.

4 Sobre el ámbito de aplicación del Reglamento, véase, A. QuiÑones EsCÁMEz, "Nuevas normas comunitarias en materia de responsabilidad parental (Reglamento (CE) no 2201/2003 del Consejo, de 27.11. 2003)", InDret, 2004. En el comentario la autora critica el que el legislador haya perdido de incluir los aspectos que afectan al ámbito patrimonial. E igualmente se ha perdido la ocasión de atender a las rupturas de pareja distintas de la matrimonial. Sin embargo, en la actualidad esta carencia ha sido corregida con el Reglamento (UE) 2016/1103 del Consejo, de 24 de junio de 2016, por el que se establece una cooperación reforzada en el ámbito de la competencia, la ley aplicable, el reconocimiento y la ejecución de resoluciones en materia de regímenes económicos matrimoniales (DOUE L 183, de 8 de julio de 2016) y el Reglamento (UE) 2016/1104 del Consejo, de 24 de junio de 2016, por el que se establece una cooperación reforzada en el ámbito de la competencia, la ley aplicable, el reconocimiento y la ejecución de resoluciones en materia de efectos patrimoniales de las uniones registradas (DOUE L 183, de 8 de julio de 2016).

${ }_{5}^{5}$ Con ello el legislador comunitario pretende facilitar, a través del Reglamento Bruselas II-bis, a los nacionales de un Estado miembro cuyo divorcio resulta imposible en la Unión Europea, el recurrir a las normas de producción interna de cada Estado miembro para conseguir una sentencia de divorcio europea. En este sentido, A.L. Calvo CaravacA, y J. CARrascosa GonZÁLEz, “Crisis Matrimoniales”, en Derecho internacional privado, vol. II, 18ª ed., Comares, Granada, 2018, pág. 234 y 235.
} 
jurídico se aplica por los tribunales de todos los Estados miembros de la Unión Europea, con la excepción de Dinamarca ${ }^{6}$.

\section{El Reglamento Bruselas II-bis: Foros de competencia judicial internacional en materia de di- vorcio, separación judicial y nulidad matrimonial.}

10. Pese a la existencia de unos foros electivos o alternativos muy amplios, el auto analizado concluye en su Fundamento de Derecho Tercero que "no nos encontramos ante ninguno de los supuestos previstos en el artículo 3 del Reglamento puesto que de la prueba que consta en autos se deduce que el último domicilio común de los cónyuges se encontraba en Francia, sin que sean atendibles las alegaciones del recurrente de que su estancia era meramente provisional".

11. Una lectura del artículo 3 RB II-bis permite concluir que los tribunales españoles serían competentes para conocer de la demanda de divorcio en el supuesto de que radicara en nuestro país: (i) la residencia habitual de los cónyuges; (ii) o el último lugar de residencia habitual de los cónyuges, siempre que uno de ellos aún resida allí; (iii) o la residencia habitual de la esposa demandada; (iv), o, en caso de demanda conjunta, la residencia habitual de uno de los cónyuges; (v) o la residencia habitual del marido demandante si ha residido allí durante al menos un año inmediatamente antes de la presentación de la demanda; (vi) o la residencia habitual del demandante en caso de que haya residido allí al menos los seis meses inmediatamente anteriores a la presentación de la demanda; (vii) o en el caso de que ambos cónyuges ostenten la nacionalidad española ${ }^{7}$.

12. En definitiva, la competencia judicial internacional en materia de divorcio, separación judicial y nulidad matrimonial se construye principalmente sobre el criterio de la residencia habitual de las partes, individual o conjuntamente consideradas (artículo 3.1 RB II-bis). Sin perjuicio de que el legislador haya contemplado también la conexión nacionalidad común de los cónyuges (artículo $3.2 \mathrm{RB}$ II-bis). El peso de la conexión residencia habitual frente a al criterio de la nacionalidad en el listado de fueros alternativos (seis foros frente a uno) resulta evidente. Y la razón es clara: la conexión residencia habitual vincula de forma más estrecha el proceso al lugar en el que los cónyuges desarrollan su vida social, laboral y familiar ${ }^{8}$.

13. En el asunto analizado los tribunales españoles podrían ser competentes para conocer de la demanda de divorcio puesto que ambos esposos tienes nacionalidad española. En este sentido, se equivoca la Audiencia Provincial cuando dice en su Fundamento de Derecho Segundo que los tribunales españoles no son competentes para conocer del divorcio. Sí lo serían en virtud del criterio de la conexión nacionalidad común. Pero, como veremos en el epígrafe siguiente ${ }^{9}$, esta competencia no sería extensible a la cuestión de la responsabilidad parental sobre los menores, y provocaría un fraccionamiento del proceso.

\footnotetext{
${ }^{6}$ Sobre la situación actual del Reino Unido, ver el art. 67 del Agreement on the withdrawal of the United Kingdom of Great Britain and Northern Ireland from the European Union and the European Atomic Energy Community (DOUE L 29, de 31 de enero de 2020).

7 P. Orejudo Prieto de los Mozos, "Diez años de aplicación e interpretación del régimen del Reglamento Bruselas II bis sobre crisis matrimoniales y responsabilidad parental (análisis de los aspectos de competencia judicial internacional)", La Ley. Unión Europea, 2014, vol. 21, pp. 5-22.

${ }^{8}$ L. A. Pérez Martín, "Trascendencia de la residencia habitual en las crisis familiares en el Derecho europeo: comentario de la sentencia de 24 de julio de 2019 de la Sección Segunda de la Audiencia Provincial de Girona", Cuadernos de derecho transnacional, 2020, vol. 12, p. 661. Además, sobre el clásico debate entre nacionalidad y residencia habitual, vid. A. RoDRíGUEZ BENot, "El criterio de conexión para determinar la ley personal: un renovado debate en Derecho Internacional Privado", Cuadernos de Derecho transnacional, 2010, vol. 2, pp. 186-202; L.A. Pérez Martín, "Propuesta de un concepto de residencia habitual de ámbito europeo en situaciones conflictivas de derecho de familia y sucesiones", Anuario Español de Derecho Internacional Privado, 2018, vol. 18, pp. 469-494.

9 Párrafo 17.
} 
14. En definitiva, la única posibilidad de plantear conjuntamente ambas cuestiones ante un mismo órgano jurisdiccional sería atendiendo al criterio de la residencia habitual. El problema consiste en localizar la residencia habitual en los supuestos de traslado de ésta a otro Estado con vocación de permanencia, cuando aquél resulta frustrado al cabo de dos únicos meses por la existencia de una crisis matrimonial sobrevenida e inesperada. Pese al escaso tiempo transcurrido desde el traslado de la residencia de la familia a Francia (en julio de 2019) hasta el momento de la interposición de la demanda de divorcio (finales de 2019), la Audiencia Provincial considerará que el traslado al país galo no tuvo carácter temporal u ocasional y que, por lo tanto, la última residencia habitual de las partes, individual o conjuntamente consideradas, está en Francia. Así argumentado, la competencia judicial internacional para conocer de la demanda de divorcio y de medidas relativas a la responsabilidad parental correspondería a los órganos jurisdiccionales franceses.

\section{El Reglamento Bruselas II-bis: Foros de competencia judicial internacional en materia de res- ponsabilidad parental}

15. El artículo 8.1 RB II-bis establece el principio de que la competencia general de los órganos jurisdiccionales de los Estados miembros en materia de responsabilidad parental se establece en función del lugar en que se encuentre la residencia habitual del menor en el momento en que se inicia un procedimiento ante el órgano jurisdiccional.

16. El artículo 13.1 del Reglamento consagra lo que ha venido denominándose la competencia residual basada en la presencia del menor para aquellos supuestos en que no pueda determinarse la residencia habitual del mismo. En estos casos, serán competentes los órganos jurisdiccionales del Estado miembro en el que esté presente el niño. Pero, como acertadamente ha manifestado en múltiples ocasiones el TJUE, la mera presencia física del menor en un Estado miembro, en cuanto norma subsidiaria respecto de la enunciada en el artículo 8 del Reglamento, no puede bastar para determinar la residencia habitual de éste ${ }^{10}$. En cualquier caso, resulta evidente que este criterio de competencia judicial internacional no sería aplicable al caso que nos ocupa, puesto que como acertadamente señala la resolución analizada no estamos ante un supuesto de menores errantes sin una residencia habitual fija.

17. Finalmente, el Reglamento comunitario prevé otro elenco de criterios de localización de la competencia judicial internacional en materia de responsabilidad parental, pero ninguno de ellos podría desplazar en el asunto analizado al criterio general de la residencia habitual de los niños menores de edad. Así, si se hubiera tratado de un tema relativo a la modificación de medidas, los tribunales españoles (es decir, los de la residencia habitual anterior del menor) seguirían siendo competentes durante los tres meses siguientes al cambio de residencia para modificar las medidas de responsabilidad parental relativas al derecho de visita dictadas en dicho Estado miembro (art. 9.1) ${ }^{11}$. Además, tampoco es posible recurrir a las dos posibilidades de prórroga de la competencia previstas en el Reglamento: una, a favor de los tribunales del Estado miembro que conocen el divorcio de los padres (forum divortii); y, otra, a favor del Estado miembro próximo o estrechamente vinculado al menor (art. 12) ${ }^{12}$. Y nos es posible porque en ambos casos sería necesario que tal prórroga hubiera sido aceptada "expresamente o de cualquier

10 STJUE de 2 de abril de 2009, asunto C-523/07, Korkein hallinto-oikeus - Finlandia (ECLI:EU:C:2009:225), ap. 33.

${ }^{11}$ Es el caso del auto de la Audiencia Provincial de las Islas Baleares 66/2018, de 19 de abril (ECLI:ES:APIB:2018:66), comentado por la Dra. D. GLUHAIA en "Residencia habitual del menor y tribunales competentes para modificar una resolución judicial sobre derecho de visita. Aplicación jurisprudencial de los artículos 8 y 9 del reglamento (CE) 2201/2003”, Cuadernos de derecho transnacional, 2019, vol. 11, pp. 751-757. O del auto 480/2019 de la Audiencia Provincial de Barcelona, de 9 de diciembre (ECLI:ES:APB:2019:11725A), comentado por la Dra. P. PeITEADO MARISCAL en "Procesos transfronterizos de modificación de medidas, residencia habitual del menor y competencia interna de los tribunales españoles", Cuadernos de derecho transnacional, 2020, vol. 12, pp. 1358-1385.

12 A. QuiÑones EscÁMEZ, "Nuevas normas comunitarias ...", Op. Cit. en materia de responsabilidad parental (Reglamento (CE) n 2201/2003 del Consejo, de 27.11. 2003)", InDret, 2004, pp. 6-9. 
otra forma inequívoca por los cónyuges o por los titulares de la responsabilidad parental en el momento de someter el asunto ante el órgano jurisdiccional y responda al interés superior del menor".

\section{Criterios delimitadores el concepto "Residencia Habitual" en el Reglamento Bruselas II-bis}

18. Enmarcado los términos del debate jurídico, el análisis de la pertinencia de la solución alcanzada por la Audiencia Provincial de Valencia radica en la interpretación que debe hacerse del concepto "residencia habitual" en el Reglamento Bruselas II-bis. Se trata de un problema planteado de forma recurrente ante los órganos jurisdiccionales internos ${ }^{13} \mathrm{y}$, por ende, ante el Tribunal de Justicia de la Unión Europea en forma de cuestión prejudicial. Ha sido este tribunal quien a través de infinidad de sentencias ha ido delimitando los perfiles de este concepto, que en múltiples ocasiones han demostrado tener un carácter muy difuso.

19. Desde este momento debemos adelantar que el Reglamento $2201 / 2003$ no contiene una definición del concepto "residencia habitual". Ante la falta de ésta no debemos aplicar, sin más, los criterios interpretativos internos de los ordenamientos jurídicos nacionales, sino que debemos recurrir a la denominada "interpretación autónoma". Es decir, para interpretar una disposición del Derecho de la Unión Europea, no solo deberemos tener en cuenta su tenor literal, sino también el contexto en el que se inscribe y los objetivos perseguidos por la normativa de la que forma parte ${ }^{14}$. Y todo ello prestando especial atención a la génesis de la disposición porque puede revelar elementos pertinentes que ayuden a su interpretación ${ }^{15}$. En concreto, el objeto perseguido por las normas de competencia de competencia judicial internacional en el ámbito de la responsabilidad parental está claramente establecido en el Considerando 12 del Reglamento Bruselas II-bis, cuando manifiesta que "están concebidas en función del interés superior del menor, y en particular en función del criterio de proximidad. Esto significa por lo tanto que son los órganos jurisdiccionales del Estado miembro en el cual el menor tiene su residencia habitual los que deben ser competentes en primer lugar, excepto en ciertos casos de cambio de residencia del menor o en caso de acuerdo entre los titulares de la responsabilidad parental" ${ }^{\prime \prime}$.

20. Además, el TJUE también nos ha advertido que la jurisprudencia relativa al concepto de residencia habitual en otros ámbitos del Derecho de la Unión europea, no puede trasladarse directamente

${ }^{13}$ En relación con el concepto de residencia habitual en el marco de la sustracción internacional de menores, en el marco del Derecho comparado resulta de gran utilidad INCADAT. Se trata de una base de datos jurídica relativa al Convenio de la Haya sobre los Aspectos Civiles de la Sustracción Internacional de Menores, accesible online y mantenida por la Conferencia de La Haya (https://www.incadat.com/es). Dentro de la sección "Análisis de jurisprudencia” se puede acceder a la jurisprudencia de diferentes Estados contratantes y proporciona estas pautas generales sobre la definición del concepto «residencia habitual»: "La interpretación del concepto central de residencia habitual (Preámbulo, art. 3, art. 4) ha demostrado ser cada vez más problemática en años recientes con interpretaciones divergentes que surgen de distintos Estados contratantes. No hay uniformidad respecto de si al momento de determinar la residencia habitual el énfasis debe estar sobre el niño exclusivamente, prestando atención a las intenciones de las personas a cargo del cuidado del menor, o si debe estar primordialmente en las intenciones de las personas a cargo del cuidado del menor. Al menos en parte como resultado, la residencia habitual puede parecer constituir un factor de conexión muy flexible en algunos Estados contratantes y mucho más rígido y reflejo de la residencia a largo plazo en otros.

La valoración de la interpretación de residencia habitual se torna aún más complicada por el hecho de que los casos que se concentran en el concepto pueden involucrar situaciones fácticas muy diversas. A modo de ejemplo, la residencia habitual puede tener que considerarse como consecuencia de una mudanza permanente, o una mudanza más tentativa, aunque tenga una duración indefinida o potencialmente indefinida, o la mudanza pueda ser, de hecho, por un plazo de tiempo definido".

${ }^{14}$ STJUE de 6 de octubre de 2020, asunto C-181/19, Jobcenter Krefeld, (ECLI:EU:C:2020:794), ap. 61 y jurisprudencia citada.

15 STJUE de 20 de diciembre de 2017, asuntos C-397/16 y C-435/16, Acacia y D'Amato, (ECLI:EU:C:2017:992), ap. 31 y jurisprudencia citada.

${ }_{16}$ STJUE de 2 de abril de 2009, asunto C-523/07, Korkein hallinto-oikeus (ECLI:EU:C:2009:225), ap. 35, 37 y 39; STJUE de 22 de diciembre de 2010, asunto C-497/10, Mercredi (ECLI:EU:C:2010:829), ap. 46 y 47; STJUE de 9 de octubre de 2014, asunto C-376/14, C (ECLI:EU:C:2014:2268), ap. 51 y 52; y STJUE de 15 de febrero de 2017, asunto, C-499/15, $W y V$ (ECLI:EU:C:2017:118), ap. 60. 
al marco de la apreciación de la residencia habitual de los menores en el sentido del artículo 8, apartado 1, del Reglamento ${ }^{17}$.

21. Expuesto lo anterior, y según un enfoque consolidado en la jurisprudencia del TJUE, la determinación de la residencia habitual supone un examen fáctico en cada asunto particular. Así, la residencia habitual del menor en el sentido del artículo 8.1 del Reglamento debe determinarse sobre la base de un conjunto de circunstancias de hecho que son particulares en cada caso. Dicho en otros términos, para fijar la residencia habitual, no sólo es necesaria la presencia física del menor en un lugar concreto, sino que deben concurrir una serie de elementos adicionales. A continuación, analizaremos los criterios delimitadores del concepto residencia habitual en la jurisprudencia del TJUE, partiendo de la premisa de que no existen dos casos iguales ${ }^{18}$.

\section{Intencionalidad de permanencia o animus manendi.}

22. La intención de permanecer en un lugar es un elemento que marca la diferencia entre la residencia habitual y una simple estancia temporal. Y ello con independencia de la duración de la misma, que constituirá un mero indicio en la evaluación de la existencia o no de estabilidad suficiente.

23. Por ello, un traslado con vocación de permanencia determina que el cambio de ubicación durante tres meses pueda conllevar un cambio de residencia habitual, mientras que una persona puede permanecer en un nuevo país durante dos años sin que esto modifique su residencia cuando el traslado se produce, por ejemplo, con ocasión de un desplazamiento temporal por motivos laborales. En definitiva, para el traslado de la residencia habitual debemos atender especialmente a la voluntad del interesado de fijar en el Estado de acogida su centro permanente o habitual de intereses con la intención de conferirle un carácter estable. No obstante, según la jurisprudencia del Tribunal de Justicia, la intención de los padres no es decisiva por sí misma para modificar la residencia habitual de un menor en el sentido del Reglamento Bruselas II-bis, aunque constituye un indicio que puede completarse con otro elenco de elementos concordantes ${ }^{19}$.

24. Así, el TJUE en su sentencia de 2 de abril de 2009, en el asunto C-523/07 afirmó que la residencia habitual de un menor, en el sentido del apartado 1 del artículo 8 del Reglamento, debía determinarse sobre la base de un conjunto de circunstancias de hecho que son particulares en cada caso. En dicho asunto, el menor había sido desplazado por sus padres de un Estado miembro a otro. La cuestión que se planteó era si su residencia habitual también había sido modificada, pese a la brevedad del tiempo transcurrido (unas pocas semanas).

25. El Tribunal analizó las circunstancias concurrentes y concluyó que la mera presencia no basta para determinar la residencia habitual a los fines del artículo 8 del Reglamento. Además de la pre-

17 STJUE de 2 de abril de 2009, asunto C-523/07, Korkein hallinto-oikeus (ECLI:EU:C:2009:225), ap. 36. Es el caso, por ejemplo, del Reglamento (CE) n ${ }^{\circ}$ 593/2008 del Parlamento Europeo y del Consejo, de 17 de junio de 2008, sobre la ley aplicable a las obligaciones contractuales (Roma I), cuyo artículo 19 define la residencia habitual de una persona física como el lugar del establecimiento principal en que dicha persona ejerce su actividad profesional.

18 Sobre el análisis de los criterios e indicios tenidos en cuenta para la determianción de la residencia habitual en casos de divorcios internacionales, vid. J. CARrascosa GonzÁLez, "La ley aplicable a la separación judicial y al divorcio en defecto de elección por los cónyuges. Análisis del artículo 8 del Reglamento 1259/2010 de 20 de diciembre 2010", Cuadernos de Derecho Transnacional, 2012, vol. 4, pp. 52-85. Y T. VIVATVARAPHOL, "Back to basics: determinig a child's habitual residence in International child abduction cases under the Hage Convention", 77 Fordham Law Review, 2008, vol. 77, pp. 3325 a 3369.

19 STJUE de 8 de junio de 2017, asunto C-111/17, OL (ECLI:EU:C:2017:436), ap. 47. Una valoración positiva de esta sentencia puede encontrarse en L. A. PÉREZ MARTín, "Residencia habitual de los menores y vulneración de derechos fundamentales: Sentencia del Tribunal de Justicia de 17 de octubre de 2018, asunto C-393/18, PPU”, La Ley Unión Europea, 2019; Y en B. Campuzano Díaz, "Una nueva sentencia del TJUE sobre el concepto de residencia habitual en el marco del Reglamento 2201/2003: sentencia de 17 de octubre de 2018, UD y XB, AS. 393/18 PPU.”, Cuadernos de derecho transnacional, 2019, vol. 11 pp. 462-471. 
sencia física del menor en un Estado miembro, deben tenerse en cuenta otros factores que puedan indicar que dicha presencia no tiene en absoluto carácter temporal u ocasional, y que la residencia del menor se traduce en una determinada integración en un entorno social y familiar. Para valorar este aspecto, el TJUE entendió que debían analizarse factores tales como la duración de la estancia, la regularidad, las condiciones y las razones de la permanencia en el territorio de un Estado miembro y del traslado de la familia a dicho Estado, la nacionalidad del menor, el lugar y las condiciones de escolarización, los conocimientos lingüísticos, las relaciones familiares y sociales del menor en dicho Estado o la compra o alquiler de una vivienda en el Estado miembro de destino ${ }^{20}$.

26. En este punto, la solución alcanzada por la Audiencia Provincial de Valencia es perfectamente compatible con esta idea de residencia habitual asociada a un animus manendi. De hecho, en su Fundamento de Derecho Segundo concluye de forma correcta que "los menores residen desde julio de 2019 de forma permanente en Francia, donde acuden al colegio y despliegan todas las facetas de su vida habitual, sin que tal estancia pueda considerarse como temporal u ocasional. Obvio es que la integración no puede resultar inmediata, pero desde luego es evidente que esa residencia tiene una vocación de permanencia y lo que se pretende es que perdure en el tiempo. Y la realidad es que el progenitor, bajo cuya custodia se encuentran los menores, lleva viviendo en Francia desde 2017, por lo que no parece razonable calificar su estancia como meramente accidental. De los indicios obrantes en autos puede deducirse que fueron ambos progenitores los que decidieron ese traslado, aun cuando la pareja ya tuviera ciertos problemas conyugales que derivaron en la solicitud de divorcio que ahora se plantea".

\section{Duración y regularidad de la residencia}

27. Otro parámetro delimitador entre la residencia habitual y la mera presencia transitoria en un lugar es la duración y continuidad de la estancia. El Reglamento Bruselas II-bis no fija ningún plazo al respecto. Según ha establecido el TJUE en reiteradas ocasiones la duración necesaria dependerá de las circunstancias de cada caso concreto, atendiendo en especial a la edad del menor y a las circunstancias familiares y sociales.

28. Así, por ejemplo, el TJUE ha manifestado que la presencia física de un menor de corta edad es un elemento determinante de la fijación de la residencia habitual ${ }^{21}$. Igualmente, el tribunal comunitario ha recalcado que los factores pertinentes varían en función de la edad del menor. Así, cuando el menor es un lactante, su entorno es esencialmente un entorno familiar, integrado por la persona, o personas, con las que vive y que cuidan de él. Y comparte necesariamente el entorno social y familiar de esa o esas personas. Todo ello es utilizado en el asunto Mercredi para concluir que cuando un lactante está efectivamente bajo la guardia de su madre en un Estado miembro distinto de aquel en el que reside habitualmente el padre, deben considerarse, por un lado, en especial la duración, la regularidad, las condiciones y las razones de la estancia de la madre en el territorio del primer Estado miembro; y por otro lado, los orígenes geográficos y familiares de la madre, así como las relaciones familiares y sociales que mantienen ésta y el menor en ese mismo Estado miembro ${ }^{22}$.

29. Finalmente, el Reglamento Bruselas II-bis nos ofrece una pauta temporal relevante ya que permite adquirir la residencia habitual en un lapso de tiempo inferior a tres meses en caso de que exista

${ }^{20}$ Sentencias del TJUE de 2 de abril de 2009, asunto C-523/07, Korkein hallinto-oikeus (ECLI:EU:C:2009:225), apartado 40, y de 22 de diciembre de 2010, asunto C-497/10, Mercredi (ECLI:EU:C:2010:829), ap. 50

${ }_{21}$ STJUE de 17 de octubre de 2018, asunto C-393/18, PPU (ECLI:EU:C:2018:835). Esta sentencia refleja la tesis ya mantenida por el TJUE indiciariamente en el asunto C-111/17 anteriormente citado, en el que en relación con la residencia habitual de un recién nacido, el tribunal manifestó que "sería dificilmente compatible con ese concepto considerar que la intención inicial de los padres de que el menor resida en un lugar determinado prima sobre el hecho de que éste haya permanecido de manera ininterrumpida en otro Estado miembro desde su nacimiento" (ap. 51).

${ }^{22}$ STJUE de 22 de diciembre de 2010, asunto C-497/10, Mercredi (ECLI:EU:C:2010:829), ap. 54 a 56. 
un cambio de la misma. Así parece inferirse del artículo 9.1 RB II-bis. Este precepto posibilita que los órganos jurisdiccionales del Estado miembro de la anterior residencia habitual del menor, durante los tres meses siguientes al cambio de residencia, sigan siendo competentes para modificar una resolución judicial sobre el derecho de visita dictada en dicho Estado miembro antes de que el menor hubiera cambiado de residencia (siempre y cuando el titular del derecho de visita continúe residiendo habitualmente en el Estado miembro de la anterior residencia habitual del menor) ${ }^{23}$. Es decir, este artículo del Reglamento Bruselas II-bis parece defender la idea de que es posible un cambio de residencia habitual antes de que transcurra el plazo de tres meses ${ }^{24}$. Teniendo en cuenta este factor, el auto de la Audiencia Provincial de Valencia tampoco incurre en contradicción con la jurisprudencia del tribunal europeo.

\section{Integración en un entorno social y familiar}

30. En su sentencia de 22 de diciembre de 2010 en el asunto Mercredi, el TJUE reiteró que el concepto de residencia habitual a efectos de los artículos 8 y 10 del Reglamento debía interpretarse en el sentido de que esa residencia se corresponde con el lugar que revela una cierta integración del menor en un entorno social y familiar.

31. Este asunto analiza el concepto de residencia habitual de un lactante de sólo dos meses de edad que se trasladó con su madre de Inglaterra a Francia. Dos semanas después del inicio del proceso en Londres, la madre incoó en Francia otro proceso. El órgano jurisdiccional inglés remitió el asunto al TJUE, que en su resolución empezó declarando que la competencia del órgano jurisdiccional de un Estado miembro en materia de responsabilidad parental respecto a un menor que se traslada lícitamente a otro Estado miembro se determina conforme al criterio de la residencia habitual de ese menor en el momento en que se presenta el asunto ante el citado órgano jurisdiccional. Además, el TJUE añadió que la edad del menor podía revestir además una especial importancia y continuó diciendo que, como regla general, el entorno de un menor de corta edad es en esencia un entorno familiar, determinado por la persona o las personas de referencia con las que vive.

32. Ese entorno es esencial para la determinación del lugar de su residencia habitual y se compone de diferentes factores variables según la edad del menor, por lo que los elementos que deben ser valorados en el caso de un menor en edad escolar difieren de los que hay que valorar si se trata de un menor de más edad o de menos edad. En esta misma línea argumental, el Abogado General JULIANE KOKOTT, en las Conclusiones presentadas el 29 de enero de 2009 en el asunto C-523/07 anteriormente mencionado afirmó que "la situación familiar viene marcada de manera decisiva por las personas de referencia con las que el menor convive en el lugar de residencia o con las que mantiene un contacto periódico, es decir, los padres, los hermanos, los abuelos u otros parientes cercanos. Relevantes para la integración social del menor son circunstancias como la escolarización, las amistades, las actividades de tiempo libre y, especialmente, el dominio del idioma".

34. Esta necesidad de integración en un entorno social no siempre ha sido correctamente entendida por nuestros órganos jurisdiccionales. Así, la sentencia de la Audiencia Provincial de Palencia de 20 de abril de $2018^{25}$ generó una situación de desamparo del niño. Concretamente se trataba de la situación de un menor, hijo de madre española y padre centroamericano, que aparecía inscrito como residente en nuestro país desde su nacimiento (el 28 de abril de 2012). Desde el año 2013 el padre se encontraba tra-

${ }^{23}$ En el ámbito de la sustracción internacional de menores, el Convenio de la Haya de 1980 ofrece un dato de suma importante pues considera que un menor que ha sido secuestrado por su progenitor y trasladado a un país distinto al de su residencia habitual se encuentra integrado en este nuevo país transcurrido un año desde que se produce el secuestro. Vid. I. LORENTE MARTíNEz, "Competencia judicial internacional de los tribunales españoles en los casos de sustracción de menores. El trato desigual en situaciones similares", Cuadernos de Derecho Transnacional, 2019, vol. 11, p. 831.

${ }^{24}$ Conclusión 48.

25 ECLI:ES:APP:2018:217 
bajando en el Reino Unido y el pequeño vivía en España con su madre. En septiembre de 2016 la pareja decidió darse una segunda oportunidad. La madre pidió una excedencia en su trabajo y se trasladó al Reino Unido con intención de establecer allí su residencia. Sin embargo, la relación personal entre los cónyuges no fue buena y ella decidió regresar con el menor a España al finalizar el curso académico en mayo de 2017. La peculiaridad del asunto radicaba en que la única conexión que el menor tenía con el Reino Unido era el hecho de que su padre se encontraba allí. Desconocía la lengua inglesa, carecía de arraigo y soporte familiar en el Reino Unido puesto que ni la familia paterna, ni la materna estaban en ese país. Su madre, su hermana y sus amigos vivían en España. Pues bien, pese a esta manifiesta falta de arraigo, la Audiencia Provincial de Palencia entendió que el traslado al país inglés se había hecho con vocación de permanencia y que, por ello, la residencia habitual del menor se encontraba en este país. Por ello, incomprensiblemente, ordenó la restitución del menor al Reino Unido. Afortunadamente la situación generada por esta resolución pudo ser corregida por los tribunales ingleses que mostraron mayor sensibilidad con el criterio del arraigo del menor que los propios tribunales españoles.

\section{Valoración final}

35. El traslado de residencia habitual con vocación de permanencia que resulta frustrado al cabo de dos únicos meses por la existencia de una crisis matrimonial sobrevenida e inesperada genera un problema de identificación del lugar de residencia habitual. La resolución analizada aplica correctamente los criterios delimitadores establecidos por el TJUE (principalmente, la intención de residir de forma estable y permanente en el Estado de acogida por parte de los cónyuges), y los indicios reveladores de la misma (escolarización, adquisición de nueva vivienda, billetes de avión de únicamente de ida...).

36. No obstante lo anterior, en este tipo de supuestos en que la ruptura sobreviene al poco de producirse el traslado del domicilio de la familia sería conveniente que los órganos jurisdiccionales valoraran adecuadamente la tensión que se genera entre la existencia de un animus manendi y la necesidad de arraigo social y familiar. Ambos criterios delimitadores pueden ser incompatibles cuando el conflicto surge en los primeros meses desde que se produce el traslado de la residencia. En estos casos no debemos olvidar que el Considerando 12 del Reglamento 2201/2003 no sólo alude al principio de proximidad como criterio inspirador del mismo, sino también a la necesidad de salvaguardar en todo caso el interés superior del menor. La solución dispensada por el artículo 15 RB II-bis puede ser una herramienta adecuada para restablecer ese equilibrio en aquellos casos en que la permanencia del menor en el estado de su nueva residencia habitual pueda suponerle un claro menoscabo para el desarrollo de su vida social y familiar. 